\title{
Teaching Reform and Practice of MIS Curriculum for MBA Using Design Thinking
}

\author{
Yuan Gao \\ College of Economics and Management \\ Northwest University \\ Xi'an China \\ tutuyuan@163.com \\ Shaofeng $\mathrm{Ru}$ \\ College of Economics and Management \\ Northwest University \\ Xi'an China \\ rsf00@163.com
}

\begin{abstract}
Design thinking, a process which fuses systemic strategy for innovation, is increasingly being recognized by educators. In this paper, we proposed a novel two stages Management Information Systems curriculum for MBA using design thinking methodology. The study enriches the literature on Management Information Systems curriculum reform in MBA education. Furthermore, it creates spectacularly transformative learning experiences for students. The two-phase of a whole journey enables students to start from learning innovations in the IT field to become an innovator who can lead IT-enabled changes in the organization.
\end{abstract}

Keywords-Design thinking; MBA curriculum; Management Information Systems; Innovation methods

\section{INTRODUCTION}

With IT becoming omnipresent, it is far more important for firms to ensure that they have active, technology-savvy leadership in place $^{[1]}$. The IT-related course has been introduced in many management schools $^{[2]}$. MIS (Management Information Systems), which aims to lead MBA(Master of Business Administration) students to know the current IT implements and link them to business in today's IT-driven world, has become one of the core course for MBA in most Business schools in the world ${ }^{[3]}$.

However, because IT changes rapidly, the content of the MIS curriculum should be dynamic as merging IT concepts of yesteryears become entrenched today. Therefore, the discussion on how to integrate the latest IT in the course and which information technologies should be included in MIS have become controversial issues ${ }^{[4,5]}$.

In this paper, we argued that three conflicts should be paid attention to when we reform the structure and organize the content of IT curriculum for MBA.

First, MBAs are different from college students who have the same major in the same department. They are the managers or experts from different parts of the area with different knowledge. Therefore, we should consider the

\author{
Yuan Fu \\ College of Economics and Management \\ Northwest University \\ Xi'an China \\ fn5501@sina.com
}

Jun Feng

College of Informatics

Northwest University

Xi'an China

fengjun@nwu.edu.cn

conflict between multi-background of MBAs and steady course contents for a successful IT course design.

Second, the MIS course has only 36 teaching hours under the pressure of business schools, squeezing the necessary part of the curriculum. There is a conflict between limited time and abundant information technologies.

Third, there is the conflict between the theory of key techniques and practice. Instead of teaching MBAs only about "what is" for information technology in the class, practice is also required for "when" and "how" to help firms to work out the "next" information system that a company may invest in.

This paper emphasizes on the teaching and learning experiences that come from dispelling the conflicts in MIS curricula by applying contemporary design thinking. We start by discussing what design thinking is and why we integrate it when reconstructing MIS course for best syncs with the overall emphasis of the school. Then we present an innovative two-phase MIS curriculum schema with design thinking. We then end with a conclusion.

\section{Evolution Methods Using DT IN MIS CURRICULUM DESIGN}

\section{A. Basic conception of design thinking}

Design thinking is defined as a process which fuses actual problem solving and abstract thinking. It is a systematic, practice-defining method of creative innovation which has been used to resolve problems in various fields ${ }^{[6]}$.

In the 2000s, IDEO introduced the concept of design thinking and brought it to the attention of businesses than any other entity. Later on, HPI D-Schools were among the first educational institutions to create a curriculum for both design students and business executives based on design thinking.

An interdisciplinary team of designers implemented the design process in five iterative stages, as showed in figure 1 . It starts with developing empathy for people they plan for. Then it defines what the problem is so as to collect information in 
various ways and furnish a variety of insights based on the gathered information inorder to uncover the real human needs they want to address. The ideate stage then generates solutions that may go beyond expected range of possibility. Finally, it turns ideas into rough prototypes and tests them with real people as designed.

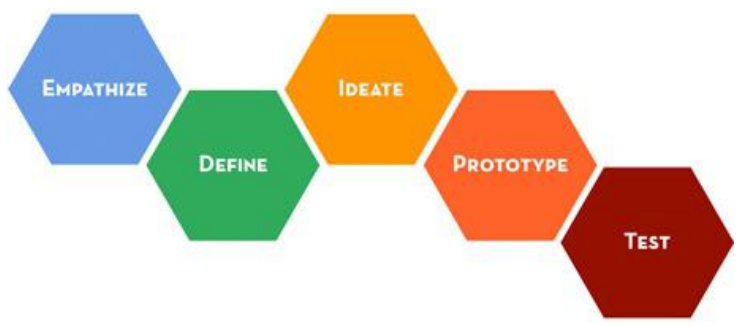

Fig. 1. Design thinking process at HPI D-Schools

\section{B. The advantages of using design thinking to realize MIS curriculum reformation}

Recently, more and more researchers engaging the intersection of design thinking and education have applied design thinking methodology to solve problems that exist in school, develop more creative curriculum, and build design thinking skills in students ${ }^{[7,8]}$.

In this paper, we use methodologies from design thinking to reform MIS course for MBA. We believe that design thinking has several advantages that can erase the conflicts we mentioned before.

\section{1) Multidiscipline is welcome}

Design thinking inspires new ways of understanding and tackling business challenges with participants from all fields and industries. The team was multidisciplinary and consists of students who have the different backgrounds which allow expanding the horizons and finding universal solutions to the problem. The methodology of DT used in the class makes it possible for MBAs to discuss around one topic or provide ideas and contribute to one project based on their perspective.

\section{2) Tools and methods ready to use for practice}

Design thinking can offer practical value as well as inspirational value for students within a design discipline. There are many tools for students willing to use for practice. They include empathy map, stakeholders map, personas, brainstorming, etc.

At the same time, the concept of design thinking methodology: H/B/T (Human values/Business/Technology) map, is used as thinking dimension in the MIS class. The corresponding Figure 2 displays the H/B/T thinking map. It accounts for three different domains at the same time: business, technology, and human value. According to $\mathrm{H} / \mathrm{B} / \mathrm{T}$ thinking dimension, a robust solution for the messy problem in the world is coming from the intersection of end user's needs with what is technologically feasible and what a viable business strategy can convert into customer value and market opportunity.

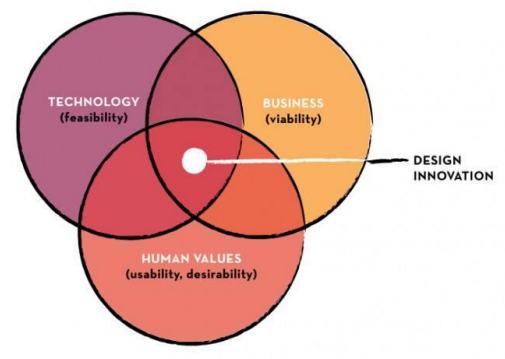

Fig. 2. H/B/T thinking dimension

\section{MIS COURSE DESIGN USING DESIGN THINKING}

The new MIS course includes two phases in theory and practice. The first phase includes five knowledge models while the second phase emphasizes the practical using design thinking. The two phases supplement each other. It realizes transformation from innovation to the innovator, which means the student not only learn what the available information technologies is to support business but also practice what they have learned to solve messy problems and become an innovator.

\section{A. Phase 1: design of IT knowledge model}

We Adopt the idea that the nature of the IS field may be more efficient to base a core question on a selection of topics ${ }^{[9]}$ We design and implement five models, each of them according to a core question and include several selected topics. This modular structure for MIS course guarantees both the completeness of curriculum system and flexibility of topic selection for each model to fit the rapid development of IT.

Design thinking holds the potential to inspire ongoing innovation. We use the methodology of design thinking in the whole teaching process. For example, when we introduce a developed or emerging technology, we encourage the student to think and discuss under the H/T/B thinking dimension. Does the technology concern feasibility and cost-effectiveness of the products, systems, and services? Does it entail for needs, wants or desires of customers? Does the business involve reliability and profitability in a market?

There are five models of the latest curriculum we designed in the business school of our university:

\section{- Model 1:}

Core content: Our survival environment.

Topic: What are the technology trends and the characteristics of the information age?

Time allotted: 2 hours

\section{- Model 2:}

Core content: IT-based business solutions

Topics: What is the information system? How do information systems influence organizational competitiveness? We introduce Optimized business solutions based on IT, including Supply chain management (SCM), Customer relationship management (CRM), Computer Supported Cooperative Work System(CSCW) and Enterprise resources 
Planning(ERP).

Time allotted: 4 hours.

- Model 3:

Core content: Data organization and management.

Topics: Why is data management so important? How do Database and Data Warehouse support businesses to realize data storage and data management? What are the opportunities and challenges when a firm meets Big Data?

Time allotted: 4 hours.

- Model 4:

Core content: Cognitive business.

Topics: What is a cognitive business? How does it influence the modern organization? The key technology introduced and discussed in this model include; Decision Support System (DSS), Artificial intelligence (AI), Big Data analytics and Visualization.

Time allotted: 2 hours.

\section{- Model5:}

Core content: New economic environment.

Topics: What is the new infrastructure of the organization? Introduces and discusses the pros and cons of emerging economic infrastructure including Ecommerce, cloud computing, Cyber-physical systems and industry 4.0 .

Time allotted: 2 hours.

\section{B. Phase two: practice of project design by design thinking}

In the first part, students learned concepts, technologies, and usages in the field of information technology. After that, they go into the practice phase. There are 16 hours for students the complexity problems in the real world by contemporary design thinking process.

\section{1) Preparation}

Students are divided into several groups with team members no more than five. Also, we assigned students who have similar profiles to separate groups. According to design thinking methodology, we believe that multidisciplinary could allow expanding the horizons and trigger out the most innovative idea to find universal solutions to the problem.

\section{2) Design thinking process}

When we first used design thinking in the MIS class, each team practice followed the five steps process of HPI D-Schools The workshop started when tutor assigned the challenge problem for all teams in the class, such as "how does the traditional commercial rescue in the E-economic environment?" However, it is difficult for MBA student to find end-user because of limited time, space and resources in the class.

To solve this problem, we adopted the idea of "scenario planning" and added "kick off" step before the traditional design thinking model. During the "kick off " stage, each team working together under the scenario that there is a venture capital looking for a most worthwhile project to invest in, so the challenging problem is finding a world messy problem based on end-user and presenting an innovative solution to win the funding. Each team started from interviewing the volunteers to finding pain spots that exist in a working or living environment and find questions about what project the team will engage in at the end of "kick off" stage.

After that, each team designs their project which covers an innovative idea into a business model through effective strategies and techniques through the design thinking process. We know that venture capital may be more willing to invest in highly speculative opportunities from high technology industries. The information technologies that they've learned and discussed in the first stage of the MIS course should be considered when creating feasible solutions.

Each team designs their project which covers an innovative idea into a business model through effective strategies and techniques. The information technology which was learned and discussed in the first phase but not limited, are recommended for use especially in the prototype step.

As the result of the design process, each group in the workshop was asked to display the prototypes and report the project to receive ratings. The team which received the highest score was the winner.

\section{CONCLUSION}

In this paper, we reformed MIS curriculum for MBA who need to know the emerging and entrenched IT/IS and how they link to a business in today's IT-driven world. Two stages curricular structure with five IT knowledge models and a design thinking workshop were introduced. Students who joined the class took a journey from learning innovations in the IT field to become an innovator who can lead IT-enabled changes in the organization.

We also collected student responses through course evaluations. Most of the students responded that the course was demanding and provided new insights for design innovation based on IT. We believe that integrating MIS with design thinking does not only enrich the curricula and expand student perspectives but also enable the abilty to turn IT based innovative idea into products and services.

\section{REFERENCES}

[1] Vol, Dhar V, Sundararajan A. Information technologies in business: A blueprint for education and research[J]. Information Systems Research. 2007, 18(2): 125-141.

[2] Wu Jun, Yang Jia-ping.Management information system curriculum reform for the inter-disciplinary talents in internet era[J]. Journal of Beijing University of Posts and Telecommunications ( Social Sciences Edition). 2016(06): 111-118. (In Chinese)

[3] Bhattacharya S, Roy R. IT for Managers: journey of a core MBA course over 10 years[J]. DECISION. 2017, 44(1): 39-50.

[4] Liu Zhi-gao.The predicament and reform breakthrough of management information system course in economics and management[J]. Chinese Education Journal. 2016(S1): 4-5. (In Chinese)

[5] Chen Mei-ling.Task oriented experimental course design of management information system[J].Education Teaching Forum. 2016(11): 264-265. (In Chinese)

[6] Brown T. Change by design: how design thinking transforms organizations and inspires innovation / 1st ed[M]. Harper Business, 2009. 
[7] Leverenz C S. Design Thinking and the Wicked Problem of Teaching Writing[J]. Computers \& Composition. 2014, 33: 1-12.

[8] Ostrowski S, Awomir, Rolczy, et al. User-friendly E-learning Platform: a Case Study of a Design Thinking Approach Use[C]. 2015.
[9] Dhar V, Sundararajan A, Brynjolfsson E, et al. Should the Core Information Systems Curriculum be Structured Around a Fundamental Question?[J]. 2004. 